\title{
While I breathe, I hope. Principles of palliative care in chronic breathlessness and advanced lung diseases
}

\author{
Eva Katharina Masel (i)
}

Received: 13 October 2019 / Accepted: 7 December 2019 / Published online: 9 January 2020 (C) The Author(s) 2020

\begin{abstract}
Summary The ancient Latin quote Dum spiro, spero from Cicero means While I breathe, I hope. This article outlines five clinically relevant principles for pulmonary palliative care to treat chronic breathlessness in advanced lung diseases: (1) be aware of the finality of life, (2) palliative care does not mean "doing nothing", (3) consider interdisciplinary and multidisciplinary therapeutic concepts, (4) conduct future talks and (5) use opioids for refractory breathlessness and think of treatable causes of respiratory distress.
\end{abstract}

Keywords Dyspnea - Neoplasms · Lung diseases · Palliative care $\cdot$ Respiration

The ancient Latin quote Dum spiro, spero from Cicero means While I breathe, I hope.

The symptom shortness of breath is the result of interactions between different physiological, psychological, social and environmental factors which in turn lead to further physiological as well as behavioral reactions [1]. It has recently been renamed as a syndrome called "chronic breathlessness" [2]. Incurable diseases in a palliative setting can lead to the syndrome of chronic breathlessness, which is characterized by chronic respiratory distress at rest or under minimal exercise despite optimal therapy of the underlying causes [3]. Palliative care and palliation comprise an active form of therapy for patients who suffer from incurable, mostly advanced illnesses. For a long period, palliative care was delivered primarily to patients suffering from oncological diseases, as

\section{E. K. Masel, MD, PhD, MSc ( $\bowtie)$}

Department of Internal Medicine I, Division of

Palliative Medicine, Medical University of Vienna,

Waehringer Guertel 18-20, 1090 Vienna, Austria

eva.masel@meduniwien.ac.at these patients were recognized as needing symptom management and attention regarding quality of life. However, the symptom burden of patients with severe chronic obstructive pulmonary disease (COPD) is comparable to that of patients suffering from lung cancer, with a significantly longer duration in survival (survival in COPD patients: median 589 days, survival in patients suffering from lung cancer: median 107 days) [4]. Therefore, non-oncological patients suffering from chronic lung diseases are likely to benefit and therefore also deserve pulmonary palliative care.

Five clinically relevant principles for pulmonary palliative care are outlined below.

\section{Be aware of the finality of life}

Since medicine is primarily focused on healing, the finite nature of life is particularly difficult to understand for doctors and medical teams, but also for patients and their caregivers. In the face of an incurable illness, a prerequisite for patients to receive palliative care is to focus on the personal wishes of the patients leaving the maximization of therapeutic options as the secondary focus in the background.

Providing good symptom control, enhancing quality of life, anticipatory planning (advance care planning) as well as involving caregivers are cornerstones of palliative care. Palliative care takes into account the principle of "high person, less technology" by palliative care pioneer Cicely Saunders. An openness to discuss topics relating to the end of life, death and dying should be regarded as a core competence for all those working in a medical profession.

\section{Palliative care does not mean "doing nothing"}

Palliative care is not limited to end of life care, but should rather be integrated into patient care at an 
Table 1 Palliative care/hospice criteria [25]

Criteria for hospice eligibility of patients with advanced lung disease

Patients will be considered to be in the terminal stage of pulmonary disease (life expectancy of six months or less) if they meet the following criteria. The criteria refer to patients with various forms of advanced pulmonary disease who eventually follow a final common pathway for end-stage pulmonary disease. (Criteria 1 and 2 should be present. Criteria 3, 4, and 5 will lend supporting documentation):

1. Severe chronic lung disease as documented by both $\mathrm{a}$ and $\mathrm{b}$ :

(a) Disabling dyspnea at rest, poorly or unresponsive to bronchodilators, resulting in decreased functional capacity (e.g., bed-to-chair existence), fatigue, and cough. (Documentation of $\mathrm{FEV}_{1}$, after bronchodilator, less than $30 \%$ of predicted is objective evidence for disabling dyspnea, but is not necessary to obtain.) (b) Progression of end-stage pulmonary disease, as evidenced by increasing visits to the emergency department or hospitalizations for pulmonary infections and/or respiratory failure or increasing physician home visits before initial certification. (Documentation of serial decrease of FEV $1>40 \mathrm{ml} / \mathrm{year}$ is objective evidence for disease progression, but is not necessary to obtain.)

2. Hypoxemia at rest on ambient air, as evidenced by $\mathrm{P}_{2}$ less than or equal to $55 \mathrm{~mm} \mathrm{Hg}$; or oxygen saturation less than or equal to $88 \%$ on supplemental oxygen determined either by arterial blood gases or oxygen saturation monitors; OR hypercapnia, as evidenced by $\mathrm{PcO}_{2} \geqslant 50 \mathrm{~mm} \mathrm{Hg}$. These values may be obtained from recent (within three months) hospital records

3. Right heart failure secondary to pulmonary disease (cor pulmonale) (e.g., not secondary to left heart disease or valvulopathy)

4. Unintentional progressive weight loss of greater than $10 \%$ of body weight over the preceding 6 months

5. Resting tachycardia $>100 / \mathrm{min}$

$\mathrm{FEV}_{1}$ forced expiratory volume, $\mathrm{PO}_{2}$ partial pressure of oxygen, $\mathrm{PCO}_{2}$ partial pressure of carbon dioxide

early stage of an incurable disease. The results of a randomized study published in the New England Journal of Medicine in the year 2010 revealed that the life of patients with stage IV lung cancer was prolonged by three months compared to standard oncology treatment by offering early palliative care after initial diagnosis [5]. The palliative care intervention consisted of caring for the patients at least once monthly by a palliative team and assessing physical and psychosocial impairments. Furthermore, the study results revealed that psychological complaints such as anxiety or depression were significantly lower in the group of patients receiving palliative care. Hence, it can be concluded that palliative care does not lead to a loss of hope. Palliation is the action management of all symptoms (physiological and psychological).

Palliative care promotes future care planning, which means patients and their families/loved ones have the opportunity to discuss and record their preferences, wishes and desires in case a situation arises when they cannot speak for themselves. Evidence tells us that patients and their caregivers appreciate being actively informed about the option of palliative care $[6,7]$.

\section{Consider interdisciplinary and multidisciplinary therapeutic concepts}

No (wo)man is an island. A recent study described a holistic approach in the form of breathing training, relaxation techniques and psychological support as a goal-oriented measure in dealing with chronic respiratory distress [8]. Respiratory therapists and respiratory outpatient clinics, as already established in the UK, are a valuable part of a pneumonology team as well as a palliative care team.

Dyspnea is what the patients says it is [9]. While respiration rate, oxygen saturation, and lung function do not provide information about the individual experience of burden, subjective assessment in the form of sensory experience, emotional stress and daily restrictions due to respiratory distress is recommended [10].

In general, physical, mental and social care, taking into account cultural as well as spiritual aspects, best describe the so-called pallium, which is synonymous with a cloak in which the patients can slip in and feel protected. In regard to advanced lung diseases, interdisciplinary cooperation benefits the patients in terms of comprehensive therapeutic concepts.

\section{Conduct future talks!}

Palliation and curation should not be considered as two mutually exclusive worldviews. The curativerestorative approach is usually geared to short-term goals, while the palliative approach focuses more on predictive planning [11]. Often, both approaches interlock and within the medical profession, one should never stop scrutinizing the facts. Even in a palliative situation, longevity may be gained by considering comorbidities, by cooperating interdisciplinarily, and importantly by giving patients the feeling of still being present when a palliative care approach-which may not be one's own field of expertise-has been initiated. Conversations about the end of life usually take place about a month before death of the patients and are mostly not conducted by the primary treating physician [12].

Patients with incurable lung diseases lack understanding of their condition and knowledge about the dynamics of COPD or similar fatal diseases and the possibility of dying from this disease, as well as patient education and reassurance of appropriate symptom management (e.g. to prevent sensation of suffocation) are well-accepted measures to help these patients [13]. Eligibility criteria for palliative care units and hospices can be found in Table 1. The article Emotions in the room: common emotional reactions to discussions of poor prognosis and tools to address them 
by Derry et al. provides a good overview of how to deal with patients' emotional responses to a poor prognosis [14].

Furthermore, the Surprise Question can serve as a helpful tool in clinical decision-making. The results of a study among general practitioners revealed that if the question, "Would you be surprised if the patient dies within the next year?" was answered with "No", the predictive value was very high and patients with palliative care needs could be well identified [15].

\section{Use opioids for refractory breathlessness and think of treatable causes of respiratory distress}

Opioids serve as a grade 1 recommendation for symptom control concerning respiratory distress in the palliation of advanced lung diseases when symptom control by using bronchodilators, diuretics, corticosteroids and other soothing measures (e.g., long-term oxygen therapy, bronchial stenting, blood transfusions, thoracocentesis, treatment of pulmonary embolism, antimicrobial therapy for pneumonia, treatment of heart failure, radiotherapy) were insufficient [16]. In COPD and pulmonary fibrosis, opioids reduce respiratory distress $[17,18]$. Opioids affect the limbic system, which leads to calmer and deeper breathing. Opioids are not used with the primary indication to sedate patients. All opioid use must be monitored for signs of opioid toxicity: myoclonus, neurological excitation, agitation and delirium.

If sedation is required to alleviate refractory symptoms, midazolam is one option which can be used in a palliative care setting $[19,20]$. Palliative sedation has been shown not to shorten life and should be regarded for a form of symptom control for severe symptoms. It is not a treatment to hasten death nor as a kind of slow euthanasia [21]. Benzodiazepines are not intended as a routine medication for breathlessness but serve as a second- or third-line therapy, benefitting patients through their anxiolytic actions [22].

Oxygen therapy through a mask or a nasal cannula is indicated only in case of proven hypoxemia. The use of a hand-held fan can be recommended to patients without hypoxemia, as trigeminal stimulation has shown to reduce symptom burden in non-hypoxic patients [23, 24].

Listen to your patients, they will tell you what they need (Cicely Saunders)! In summary, acquiring palliative care skills can lead to better management of those with serious illnesses and can help patients cope with their illnesses better.

Funding Open access funding provided by Medical University of Vienna.

Conflict of interest E.K. Masel declares that she has no competing interests.

Open Access This article is licensed under a Creative Commons Attribution 4.0 International License, which permits use, sharing, adaptation, distribution and reproduction in any medium or format, as long as you give appropriate credit to the original author(s) and the source, provide a link to the Creative Commons licence, and indicate if changes were made. The images or other third party material in this article are included in the article's Creative Commons licence, unless indicated otherwise in a credit line to the material. If material is not included in the article's Creative Commons licence and your intended use is not permitted by statutory regulation or exceeds the permitted use, you will need to obtain permission directly from the copyright holder. To view a copy of this licence, visit http://creativecommons. org/licenses/by/4.0/.

\section{References}

1. Anonymous. Dyspnea. Mechanisms, assessment, and management: a consensus statement. American Thoracic Society. Am J Respir CritCare Med. 1999;159:321-40.

2. Johnson MJ, Yorke J, Hansen-Flaschen J, Ekström M, Currow DC. Chronic breathlessness: re-thinking the symptom. Eur Respir J. 2018;51. https://doi.org/10.1183/13993003. 00340-2018.

3. Abernethy AP, Currow DC, Frith P, Fazekas BS, McHugh A, Bui C. Randomised, double blind, placebo controlled crossover trial of sustained release morphine for the management of refractory dyspnoea. BMJ. 2003;327:523-8.

4. Bausewein C, Booth S, Gysels M, Kühnbach R, Haberland B, Higginson IJ. Understanding breathlessness: crosssectional comparison of symptom burden and palliative care needs in chronic obstructive pulmonary disease and cancer. J Palliat Med. 2010;13:1109-18.

5. Temel JS, Greer JA, Muzikansky A, Gallagher ER, Admane S, Jackson VA, et al. Early palliative care for patients with metastatic non-small-cell lung cancer. N Engl J Med. 2010;363:733-42.

6. McDonald J, Swami N, Hannon B, Lo C, Pope A, Oza A, et al. Impact of early palliative care on caregivers of patients with advanced cancer: cluster randomised trial. Ann Oncol. 2017;28:163-8.

7. FerrellBR, TemelJS, TeminS, AlesiER, BalboniTA, BaschEM, et al. Integration of palliative care into standard oncology care: American Society of Clinical Oncology Clinical Practice Guideline update. JClin Oncol. 2017;35:96-112.

8. Maddocks M, Brighton LJ, Farquhar M, Booth S, Miller S, Klass L, et al. Holistic services for people with advanced disease and chronic or refractory breathlessness: a mixedmethods evidence synthesis [Internet]. Southampton(UK): NIHR Journals Library. 2019. http://www.ncbi.nlm.nih. gov/books/NBK543046/. Accessed 1 Sept 2019.

9. BakerKM,DeSanto-MadeyaS, BanzettRB. Routinedyspnea assessment and documentation: Nurses' experience yields wide acceptance. BMCNurs. 2017;16:3.

10. Parshall MB, Schwartzstein RM, Adams L, Banzett RB, Manning HL, Bourbeau J, et al. An official American Thoracic Society statement: update on the mechanisms, assessment, and management of dyspnea. Am J Respir Crit Care Med. 2012;185:435-52.

11. Taylor DR, Murray SA. Improving quality of care for endstage respiratory disease: Changes in attitude, changes in service. Chron Respir Dis. 2018;15:19-25.

12. Burki TK. End-of-life discussions and care received. Lancet Oncol. 2013;14:16.

13. Robinson J, Gott M, Gardiner C, Ingleton C. A qualitative study exploring the benefits of hospital admissions from the perspectives of patients with palliative care needs. Palliat Med. 2015;29:703-10. 
14. Derry HM, Epstein AS, Lichtenthal WG, Prigerson HG. Emotions in the room: common emotional reactions to discussions of poor prognosis and tools to address them. Expert RevAnticancer Ther. 2019;19:689-96.

15. Moroni M, Zocchi D, Bolognesi D, Abernethy A, Rondelli R, Savorani G, et al. The "surprise" question in advanced cancer patients: A prospective study among general practitioners. Palliat Med. 2014;28:959-64.

16. Janssen DJA, Spruit MA, Schols JMGA, Wouters EFM. A dosage of opioids should never exceed what is necessary to relieve symptoms. Am J Respir Crit Care Med. 2008;178:1186. author reply 1186.

17. Rajala K, Lehto JT, Saarinen M, Sutinen E, Saarto T, Myllärniemi M. End-of-life care of patients with idiopathic pulmonary fibrosis. BMC Palliat Care. 2016;15:85.

18. Ekström M, Nilsson F, Abernethy AA, Currow DC. Effects of opioids on breathlessness and exercise capacity in chronic obstructive pulmonary disease. A systematic review. Ann Am Thorac Soc. 2015; 12:1079-92.

19. Mercadante S, Porzio G, Valle A, Fusco F, Aielli F, Costanzo V, et al. Palliative sedation in patients with advanced cancer followed at home: a systematic review. J Pain Symptom Manage. 2011;41:754-60.

20. Schur S, Weixler D, Gabl C, Kreye G, Likar R, Masel EK, et al. Sedation at the end of life-a nation-wide study in palliative care units in Austria. BMC Palliat Care. 2016;15:50.

21. Schofield G, Baker I, BullockR, ClareH, ClarkP, Willis D, etal. Palliative opioid use, palliative sedation and euthanasia: reaffirming the distinction. J Med Ethics. 2019. https:// doi. org/10.1136/medethics-2018-105256.

22. Simon ST, Higginson IJ, Booth S, Harding R, Weingärtner V, Bausewein C. Benzodiazepines for the relief of breathless- ness in advanced malignant and non-malignant diseases in adults. Cochrane Database Syst Rev. 2016;10:CD7354.

23. Johnson MJ, Booth S, Currow DC, Lam LT, Phillips JL. A mixed-methods, randomized, controlled feasibility trial to inform the design of a phase III trial to test the effect of the handheld fan on physical activity and carer anxiety in patients with refractory breathlessness. J Pain Symptom Manage. 2016;51:807-15.

24. Galbraith S, Fagan P, Perkins P, Lynch A, Booth S. Does the use of a handheld fan improve chronic dyspnea? A randomized, controlled, crossover trial. J Pain Symptom Manage. 2010;39:831-8.

25. Lanken PN, Terry PB, Delisser HM, Fahy BF, HansenFlaschen J, Heffner JE, et al. An official American Thoracic Society clinical policy statement: palliative care for patients with respiratory diseases and critical illnesses. Am JRespir Crit Care Med. 2008;177:912-27.

Publisher's Note Springer Nature remains neutral with regard to jurisdictional claims in published maps and institutional affiliations.

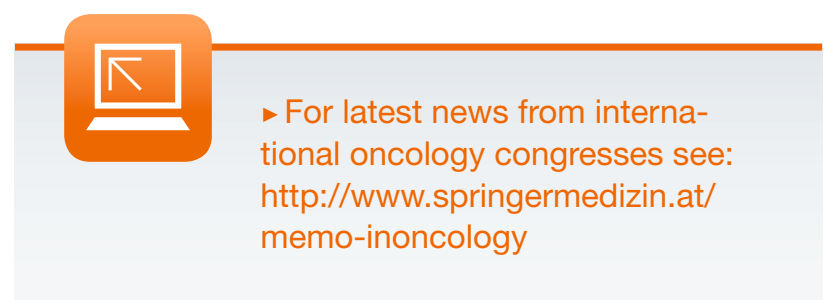

